\title{
Renal cell carcinoma metastases to the pancreas and the thyroid gland 19 years after the primary tumour
}

\author{
Sylwia Wolf1, Lukasz Obolonczyk ${ }^{1}$, Krzysztof Sworczak' ${ }^{1}$, Piotr Czapiewski², Zbigniew Sledzinski ${ }^{3}$ \\ ${ }^{1}$ Department of Endocrinology and Internal Medicine, Medical University of Gdansk, Gdansk, Poland \\ 2Department of Pathomorphology, Medical University of Gdansk, Gdansk, Poland \\ ${ }^{3}$ Department of General, Endocrine and Transplant Surgery, Medical University of Gdansk, Gdansk, Poland
}

Prz Gastroenterol 2015; 10 (3): 185-189

DOI: $10.5114 / p g .2015 .49000$

Address for correspondence: Sylwia Wolf, Department of Endocrinology and Internal Medicine, Medical University of Gdansk,
16/59 Bitwy Oliwskiej St, 80-339 Gdansk, Poland, phone: +48 505803 590, fax: +48 583492 841, e-mail: sylviam@op.pl

Renal cell carcinoma (RCC) is a relatively rare solid tumour: it comprises ca. 3\% of all malignant neoplasms among adults. The most common histological RCC type (70-80\% of renal neoplasms) is clear cell cancer. At diagnosis $30 \%$ of patients with this tumour have distant metastases, and in $20 \%$ of cases it is considerably advanced locally [1, 2]. Moreover, following nephrectomy, $20 \%$ to $30 \%$ of RCC patients in whom the tumour only affects the kidneys, on average will have a local recurrence and/or distant metastases after 15 to 18 months, while in $85 \%$ the disease will recur within 3 years [3]. Metastases may also appear more than 10 years after surgical treatment. The most common metastatic sites for bloodstream-spread are the lungs, liver, brain, and bones $[3,4]$. The second way in which the tumour can spread is via the lymphatic vessels. Renal cell carcinoma patients may have distant metastases in atypical locations, i.e. the skin, thyroid, and pancreas. Resectable RCC metastases found in post-nephrectomy follow-ups should be removed surgically since metastasectomy sometimes enables long-term survival [2].

A 61-year-old woman was admitted to the Department of Endocrinology and Internal Medicine in February 2013 because of multiple pancreatic tumours. Nineteen years earlier she underwent left nephrectomy due to RCC, after which she was not followed-up, either urologically or oncologically. In October 2012 there was a single episode of haematuria; the patient had an abdominal ultrasound performed (8 January 2013), which revealed a $19-\mathrm{mm}$ mass on the border of the body and neck of the pancreas. In an abdominal computed tomography (CT) scan (10 January 2013) multiple (at least 6) masses were found in the pancreas, the largest of them was located in the head and measured $35 \mathrm{~mm}$ in diameter, and had central necrosis. The character of the masses was suggestive of multiple pancreatic neuroendocrine tumours. In a magnetic resonance imaging (MRI) scan (31 January 2013) the masses were described as ambiguous, i.e. "their characteristics could match those of neuroendocrine tumours; however, the biggest of masses, with necrosis, might have a different aetiology; on account of the patient's oncological history, metastatic tumours cannot be excluded (...)".

Moreover, since at least 2004, two masses in the thyroid gland had been observed in this patient. Cytology result of the right-lobe mass fine needle aspiration biopsy (FNAB) material suggested normal follicular thyroid cells. Over several years the diameter of the tumour increased from $22 \mathrm{~mm}$ to $27 \mathrm{~mm}$.

The patient had the following complaints for about 3 years: fatigue, polyuria, nycturia; she lost $3 \mathrm{~kg}$ of body weight in 2 months; she was diagnosed with diabetes mellitus (DM) which was treated with diet.

On admission the patient was in a good general condition; the physical examination abnormalities were overweight, nodular goitre with a palpable 2-cm mass in the gland's right lobe, and a silent systolic murmur over the tricuspid valve.

Laboratory results showed impaired fasting glucose (103 mg/dl), whereas thyroid hormones, carcinoembryonic antigen (CEA), and Ca19.9 neoplasmatic marker concentrations were within reference ranges.

The imaging studies, CT (Figure 1), and MRI abdominal scans, were examined by a radiologist, who described the masses as highly suggestive of RCC metastases.

During the hospitalisation a thyroid sonography (Figure 2) was performed; in the right lobe a highly distress- 


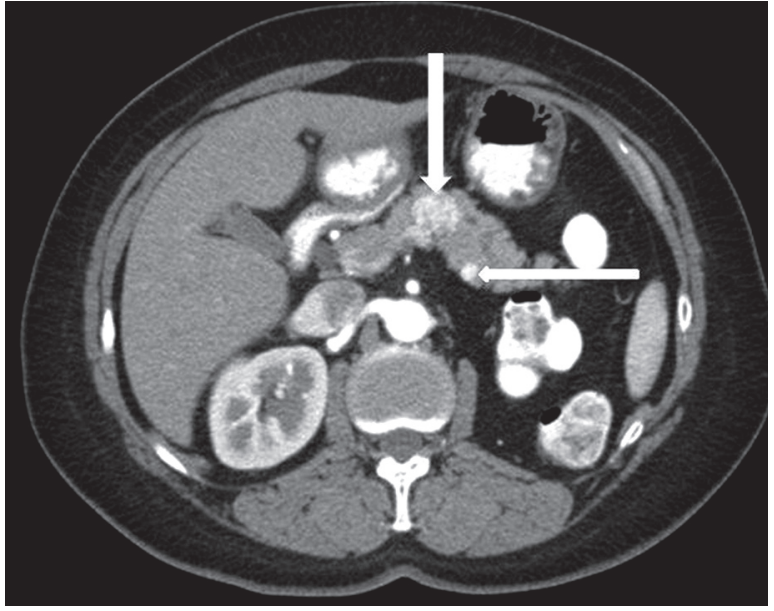

Figure 1. Computed tomography scan shows RCC metastases to the pancreas (arrows)

ing tumour was found, measuring $35 \times 24 \times 39.4 \mathrm{~mm}$, with a rich peripheral and central vasculature in the power Doppler (PD) feature. The mass was clearly larger than in previous sonographies. In the left lobe a focal solid-cystic mass was found, which measured $12.8 \times$ $8.4 \times 16.2 \mathrm{~mm}$, had a halo, and also peripheral-central vasculature in PD sonogram.

Taking into consideration the clinical presentation, imaging, and laboratory results a suspicion of multiple RCC metastases to the pancreas and the thyroid gland was put forward. The patient was qualified for surgical treatment, i.e. pancreatectomy and thyroidectomy.

On 21 March 2013 she underwent total pancreatectomy in the Department of General, Endocrinological, and Transplant Surgery. Four tumours were found in the pancreas on laparotomy: a 3-cm tumour in the head, a $1-\mathrm{cm}$ tumour in the body, a $0.5-\mathrm{cm}$ tumour on the frontal surface of the body, and a $2-\mathrm{cm}$ tumour in the tail of the pancreas (Figure 3). These findings prompted the decision to extend the scope of surgery to include (as well as total pancreatectomy) splenectomy and cholecystectomy, which were performed along with a pylorus-sparing reconstruction and hepaticojejunostomy.

Histopathological examination confirmed the RCC metastases suspicion (Figure 4). The neoplasm had a CD10(+), RCC(+) phenotype. No metastases were found in the lymph nodes, spleen, or gallbladder; the surgical margin was free of cancer too.

After the surgery the patient was consulted with a diabetologist, and insulin and pancreatic enzyme replacement were implemented. She was released several days later in good condition. Awaiting thyroidectomy the patient noticed a protrusion on the right side of her neck.

On 19 May 2013 she was again admitted to the above-mentioned surgical department where she underwent total thyroidectomy with central compartment neck dissection (21 May). Histologically (Figure 5) a RCC metastasis to the thyroid was found; the gland structure was nodular. The neoplasmatic phenotype was $\mathrm{CD} 10(+), \mathrm{RCC}(+)$, thyreoglobulin(-). The resection was complete.

Following surgery the patient was supplemented with vitamin D, calcium, and L-thyroxin. She was referred to the endocrine outpatient clinic.

Renal cell carcinoma is an uncommon neoplasm with a varying clinical presentation. Up to $30 \%$ of RCC patients have metastases on diagnosis; about $50 \%$ of the remaining patients have a recurrence of the dis-
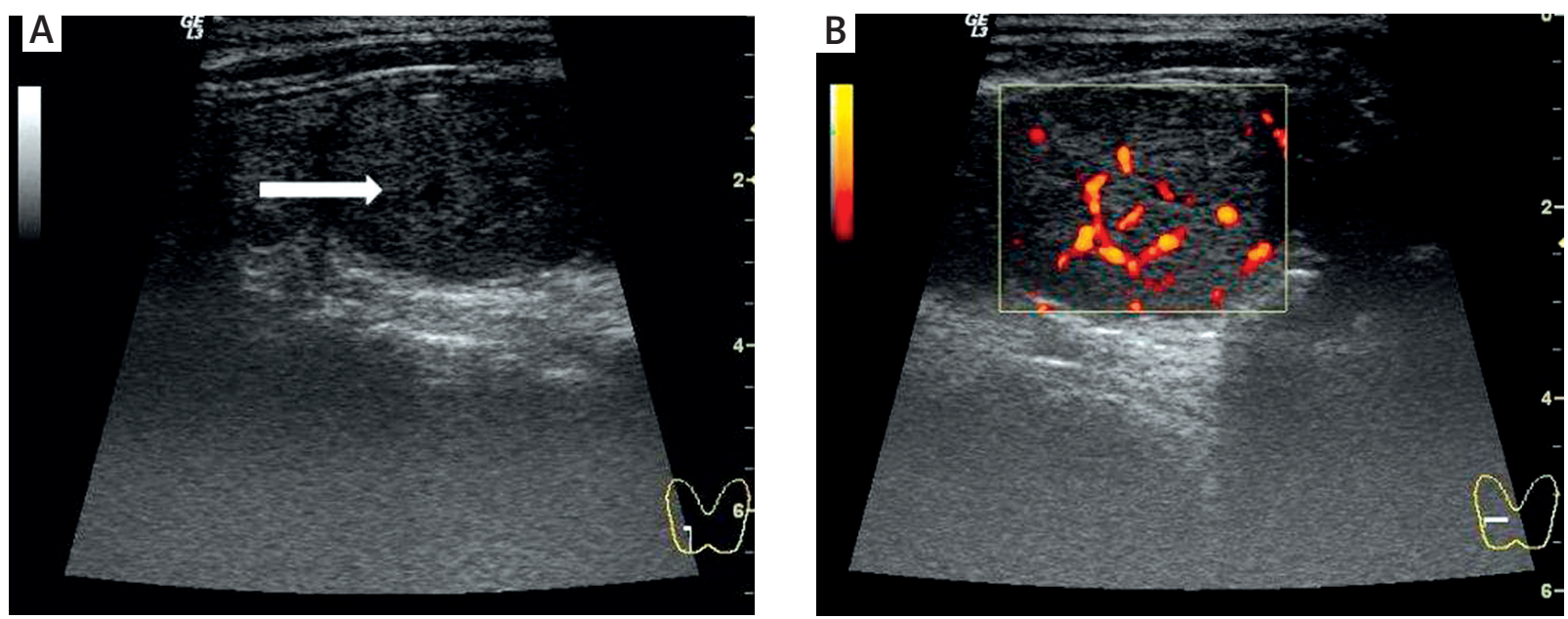

Figure 2. A - Ultrasound picture with large, solid, hypoechoic tumour in right thyroid lobe (arrow). B - PD ultrasound - rich peripheral and central vasculature in right lobe tumour 
ease following nephrectomy. There are several factors influencing the survival rate of patients with RCC metastases: the size and number of metastatic foci, the patient's general condition, and the duration of disease-free interval [2, 5].

The described case is very rare. In the literature there are very few reports of patients undergoing radical surgery of multifocal multiple RCC metastases [6].

Renal cell carcinoma metastasises through the bloodstream and/or lymphatic vessels [1, 2]. Renal cell carcinoma spreads to the pancreas via the haematogenous route $[2,7]$. In the presented case, abdominal lymph node involvement was not stated. Renal cell carcinoma metastases to the thyroid gland are also haematogenous; however, it is not fully understood how thyroid metastases take place without lung involvement. One hypothesis suggests transfer of cancerous cells through lung capillaries before reaching the thyroid gland, and an alternative route may be through the paravertebral venous plexi [8].

Patients with singular metastases and long disease-free interval (lasting over 12 months) have a favourable prognosis [2]. Although complete resection
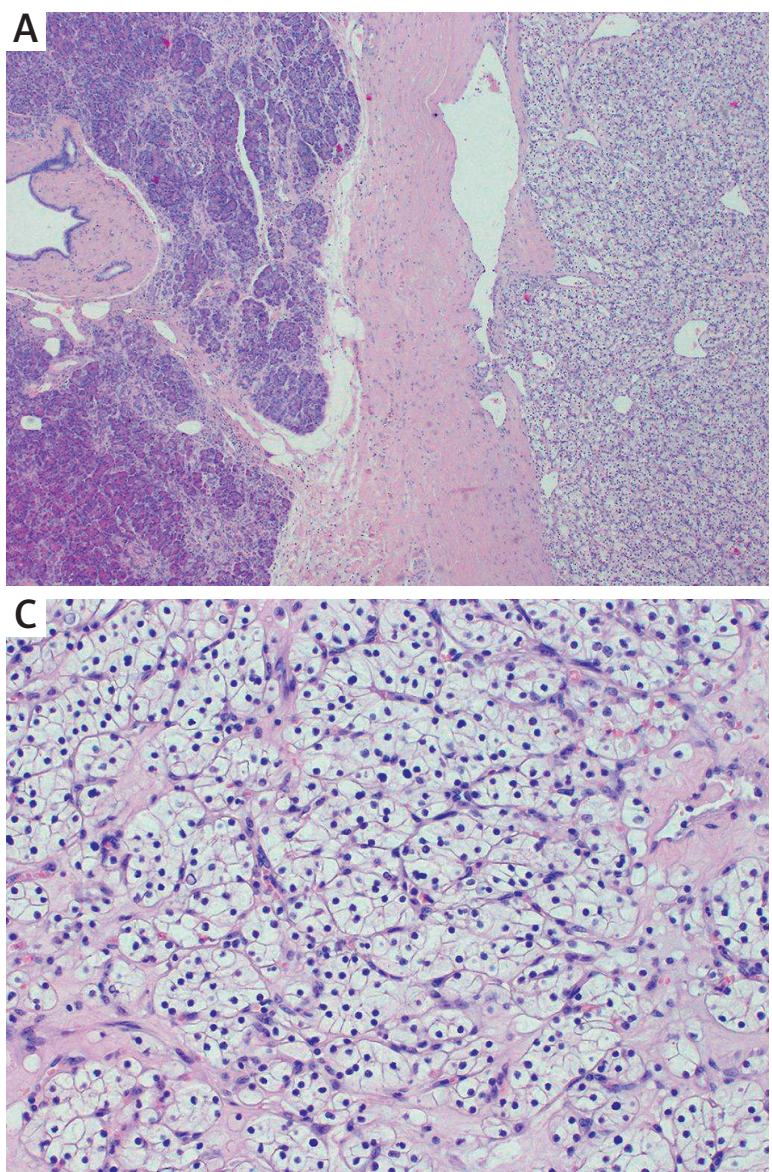

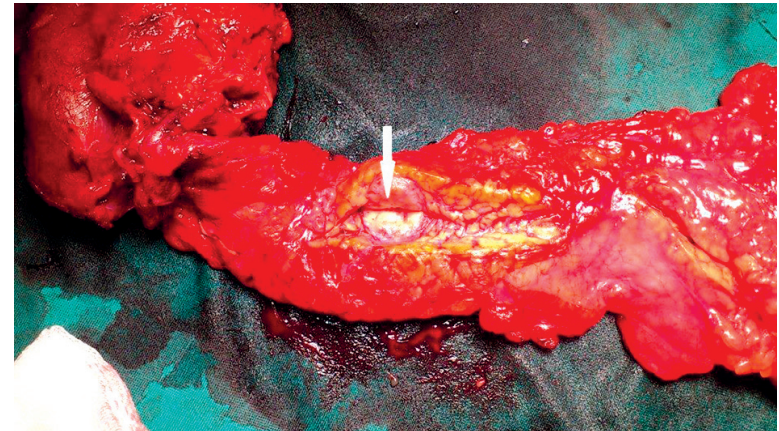

Figure 3. One of the four metastases to the pancreas after surgery

of single metastasis is associated with a $35 \%$ to $60 \%$ 5 -year survival, there are only a handful of reports on aggressive surgical treatment of patients with multiple metastases [2, 9-11]. Some authors stress that the number of resected metastases foci does not influence 5-year survival, and instead they have shown that it depends solely on radical metastasectomy [10, 12].

Metastases to the pancreas are found rarely: in autopsy studies of late-stage neoplasmatic disease

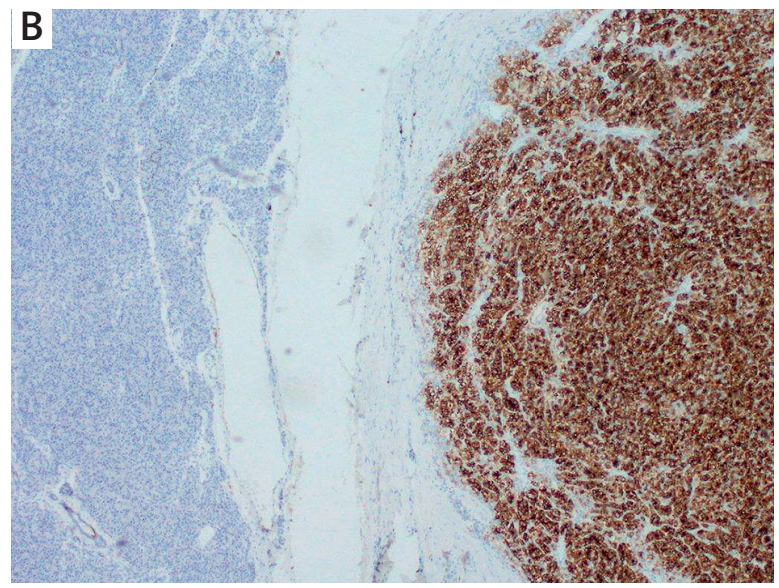

Figure 4. A - Pancreas tissue (on the left) is separated from the metastatic RCC (on the right) by a thick connective tissue capsule (in the middle of the picture). B - Intensive membranous reaction with antibody against CD10. Pancreatic tissue remains negative. $\mathbf{C}$ - Neoplastic cells from pancreatic tumour show typical for RCC clear cytoplasm, highly vascularised stroma and foci of hyalinisation 
patients their frequency was between $1.6 \%$ and $11 \%$, while clinically $2 \%$ to $5 \%$ of all pancreatic neoplasms are metastases [3, 13-15]. Renal cell carcinoma metastases to the pancreas represent only $0.25 \%$ to $2.8 \%$ of patients $[2,3,7,14,16,17]$. In long-term observation the mean time from radical nephrectomy to the diagnosis of pancreatic metastasis was 8 to 12 years [2]. The longest disease-free interval following radical nephrectomy until a pancreatic metastasis was found was 32.7 years [15]. In the presented case it was 19 years.

Secondary (metastatic) cancers of the thyroid gland are a rarity. They comprise clinically barely $0.5 \%$ of all thyroid neoplasms [18]. Secondary thyroid cancer does not allow for an easy diagnosis. In $70 \%$ of cases the primary source of thyroid metastases is the $\operatorname{RCC}[8,18]$. Most authors believe 1\% to $5 \%$ of RCC metastases are localised in the thyroid gland $[4,19,20]$. Thyroid metastases are most commonly metachronic and appear earlier than in the pancreas $[6,20]$. Mean time from nephrectomy due to RCC to the diagnosis of thyroid metastasis is about 10 years [20], and the longest disease-free interval following radical nephrectomy was 24 years [21]. Renal cell carcinoma metastases to the thyroid are macroscopically similar to primary thyroid neoplasms [21]. In the reported case the cytological examination preceding the surgery revealed normal thyroid cells, while histological examination after thyroidectomy demonstrated RCC cells in the nodular goitre tissue (Figure 5).

Several authors have reported long-term survival after surgical metastasectomy in RCC [1, 2, 18, 22]. Renal cell carcinoma metastases to the pancreas are usually singular and symptomatic. Patients suffer from bleeding in the digestive tract, abdominal pain, jaundice, chronic pancreatitis, and/or weight loss. In some cases RCC metastases are asymptomatic and are diagnosed in regular post-nephrectomy follow-up examinations.

As a rule, RCC metastases to the thyroid gland do not produce symptoms. Advanced tumours mimic primary thyroid cancer symptoms. Sometimes metastases are found in nodular goitre [23], just as in the discussed case.

Treatment of metastatic neoplasms using methods such as interferon $\alpha$, chemo-, hormonal, and biological therapy are less effective than total surgical resection of RCC metastases in terms of 5-year survival. Radical resection, where applicable, is recommended for these lesions for improved survival and better quality of life $[14,17,22]$.
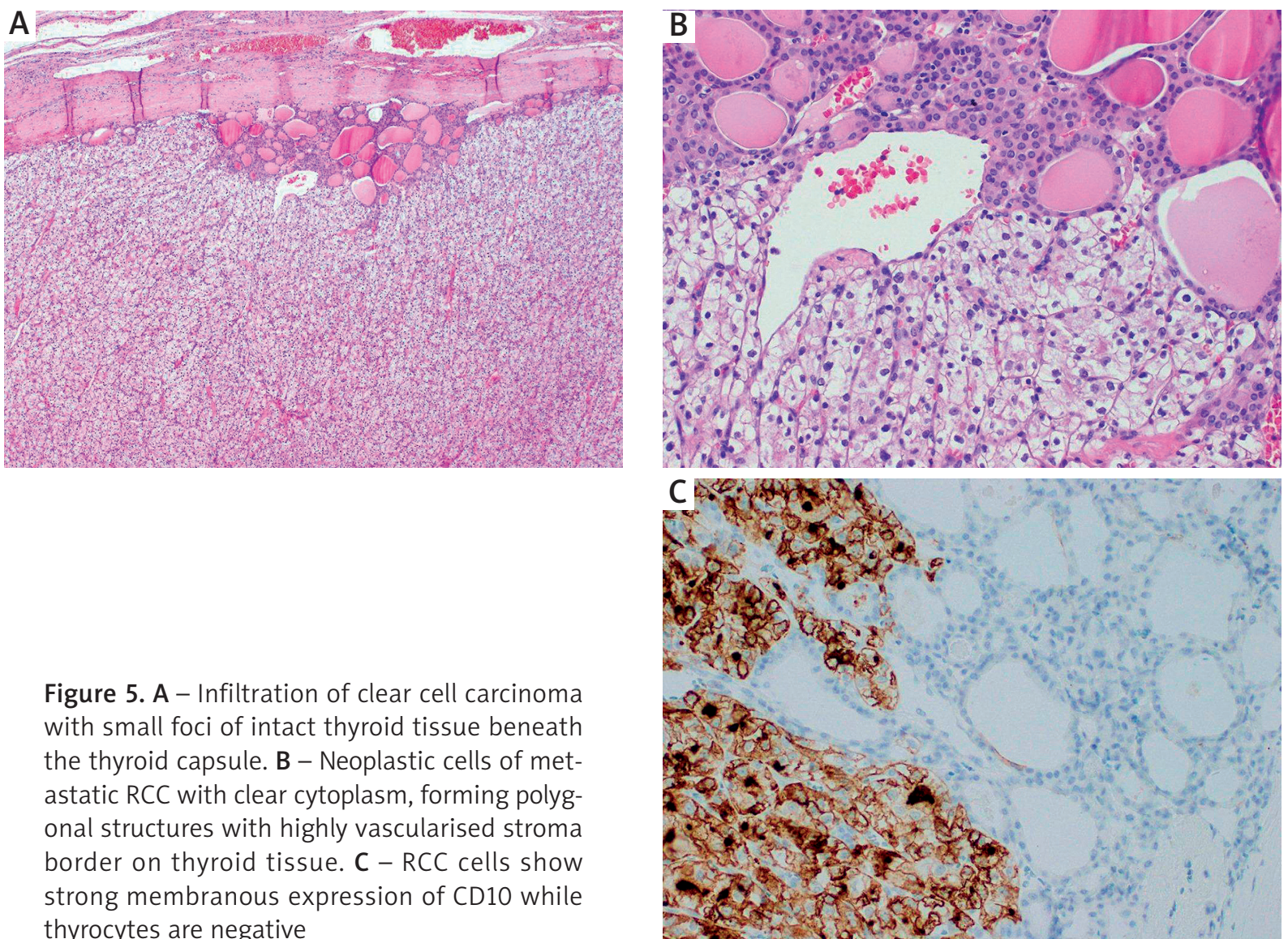

Figure 5. A - Infiltration of clear cell carcinoma with small foci of intact thyroid tissue beneath the thyroid capsule. B - Neoplastic cells of metastatic RCC with clear cytoplasm, forming polygonal structures with highly vascularised stroma border on thyroid tissue. C - RCC cells show strong membranous expression of CD10 while thyrocytes are negative 
The reported case indicates the necessity of longterm follow-up of RCC patients as a means of early diagnosing of metastases to the pancreas, thyroid gland, and other organs. This report also underlines the need for special attention in radiological and histopathological diagnostics, and it substantiates metastasectomy in patients in good general condition.

\section{Conflict of interest}

The authors declare no conflict of interest.

\section{References}

1. Martel CL, Lara PN. Renal cell carcinoma: current status and future directions. Critical Rev Oncol Hematol 2003; 45: 177-90.

2. Hać S, Sworczak K, Rzepko R. Pancreatic multiple metastases of renal cell carcinoma - case report. Wspolczesna Onkol 2007; 11: 220-2.

3. Schauer M, Vogelsang $\mathrm{H}$, Siewert JR. Pancreatic resection for metastatic renal cell carcinoma: a single center experience and review of the literature. Anticancer Res 2008; 28: 361-6.

4. Demir L, Erten C, Somali I, et al. Metastases of renal cell carcinoma to the larynx and thyroid. Two case reports on metastasis developing after nephrectomy. Can Urol Assoc J 2012; 6: 209-12.

5. Giuliani L, Giberti C, Martorana G, Rovida S. Radical extensive surgery for renal cell carcinoma: long term results and prognostic factors. J Urol 1990; 143: 468-73.

6. lesalnieks I, Winter H, Bareck E, et al. Thyroid metastases of renal cell carcinoma: clinical course in 45 patients undergoing surgery. Assessment of factors affecting patients' survival. Thyroid 2008; 18: 615-24.

7. Thompson LD, Heffess CS. Renal cell carcinoma to the pancreas in surgical pathology material. Cancer 2000; 89: 1076-88.

8. Sworczak K, Mizan K, Szałach E. Solitary metastasis of the clarocellular renal carcinoma to the thyroid. Pol Arch Med Wewn 1990; 84: 30-5.

9. Law $\mathrm{CH}$, Wei AC, Hanna SS, et al. Pancreatic resection for metastatic renal cell carcinoma: presentation, treatment, and outcome. Ann Surg Oncol 2003; 10: 922-6.

10. Tuech JJ, Pessaux P, Chautard D, et al. Results of duodenopancreatectomy for solitary pancreatic metastasis from renal cell carcinoma. J Hepatobiliary Pancreat Surg 1999; 6: 396-8.

11. Yachida S, Fukushima N, Kanai Y, et al. Pancreatic metastasis from renal cell carcinoma extending into the main pancreatic duct: a case report. Jpn J ClinOncol 2002; 32: 315-7.

12. Faure JP, Tuech JJ, Richer JP, et al. Pancreatic metastasis of renal cell carcinoma: presentation, treatment and survival. J Urol 2001; 165: 20-2.

13. Fricke P, Schulz HU, Buhtz P, Lippert H. Multiple metachronous metastases of renal cell carcinoma in the pancreas. Case report and review of the literature. Chirurg 2000; 71: 575-9.

14. Aimoto T, Uchida E, Yamahatsu K, et al. Surgical treatment for isolated multiple pancreatic metastases from renal cell carcinoma: report of a case. J Nippon Med Sch 2008; 75: 221-4.

15. Ballarin R, Spaggiari $M$, Cautero N, et al. Pancreatic metastases from renal cell carcinoma: the state of the art. World J Gastroenterol 2011; 17: 4747-56.
16. Z'graggen K, Fernandez-del Castillo C, Rattner DW, et al. Metastases to the pancreas and their surgical extirpation. Arch Surg 1998; 133: 413-7.

17. Comunoğlu C, Altaca G, Demiralay E, Moray G. Multiple metastatic renal cell carcinoma isolated to pancreas. Malays J Pathol 2012; 34: 63-6.

18. Siekierska-Hellmann M, Sworczak K, Lewczuk A, et al. Renal cell carcinoma with solitary metastases appearing during 18 years of follow-up. Postgrad Med J 1997; 73: 582-4.

19. Skyes TC, Patel A, Archer D, et al. Parotid metastasis from renal carcinoma. Br J Urol 1995; 76: 398-9.

20. Garcia-Olaverri Rodriguez J, Villafruela Mateo A, Azurmendi Arin I, et al. Metachronic thyroid metastasis secondary to renal carcinoma. Arch Esp Urol 2007; 60: 697-9.

21. Di Stasi V, D'Antonio A, Caleo A, Valvano L. Metastatic renal cell carcinoma to the thyroid gland 24 years after the primary tumour. BMJ Case Rep 2013 Jan 25. pii: bcr2012007569. doi: 10.1136/bcr-2012-007569.

22. Bassi C, Butturini G, Falconi $\mathrm{M}$, et al. High recurrence rate after atypical resection for pancreatic metastases from renal cell carcinoma. Br J Surg 2003; 90: 555-9.

23. Bohn OL, De las Casas LE, Leon ME. Tumor-to-tumor metastasis: Renal cell carcinoma metastatic to papillary carcinoma of thyroid - report of a case and review of the literature. Head Neck Pathol 2009; 3: 327-30.

Received: 21.08 .2014

Accepted: 28.10.2014 